\title{
Capitalismo de chupacabras en una era post-política y post-migratoria
}

\author{
Alyshia Gálvez \\ José Carlos Luque-Brazán \\ New School, New York \\ Universidad Autónoma de la Ciudad de México, México
}

\section{Resumen}

La presente investigación reflexiona sobre el tipo de capitalismo en el que se inserta el actual fenómeno migratorio en México. Se argumenta que existe una relación implícita entre neoliberalismo, migración, ciudadanía y estado. Un proceso en donde las vinculaciones políticas tejidas en torno al estado se difuminan y los derechos de las personas se mercantilizan o pierden sentido progresivamente. En este sentido el capitalismo "chupacabras", se fija en las depredaciones de los cuerpos de los migrantes. Se teoriza que esta nueva forma de capitalismo voraz se abalanza de cuatro maneras sobre los migrantes: 1) los despolitiza de sus derechos humanos y de ciudadanía; 2) elimina los cuerpos sobrantes. 3) Los recategoriza como una amenaza al estado y a la sociedad y por tanto los hace sujetos a la violencia o neutralización por parte de cualquier agente del estado o actores para-estatales, y; 4) finalmente, los presiona hacia el consumo y hacia el trabajo clandestino, lo cual a su vez, en su máxima expresión, disminuye casi totalmente las demandas que pueden hacer en el estado para hacer visible o denunciar sus condiciones de vida.

Palabras claves: Capitalismo de chupacabras, neoliberalismo, post-migración, postpolítica.

\section{Capitalism and the Chupacabras in a Post-Political and Post-Migration Era}

\section{Abstract}

The present investigation reflects on the type of capitalism in which the current migratory phenomenon in Mexico is inserted. It is argued that there is an implicit relationship between neoliberalism, migration, citizenship and the state. A process in which the political links woven around the state are blurred and the rights of people become commodified or lose their meaning progressively. In this sense, capitalism chupacabra, is fixed in the depredations of the bodies of migrants. It is theorized that this new form of voracious capitalism encroaches in four ways on migrants: 1) it depoliticizes their human rights and citizenship; 2) removes their leftover bodies; 3 ) Recategorizes them as a threat to the state and society and therefore makes them subject to violence or neutralization by any State agent or para-state actors, and; 4) finally, it pushes them towards consumption and towards clandestine work, which in turn, at its maximum expression, diminishes almost completely the demands that can be made in the State to make visible or denounce their living conditions.

Key words: Chupacabras capitalism, neoliberalism, post-migration, post-politics.

Recibido: 29 de noviembre de 2018

Aprobado: 22 de marzo de 2019 
La tradición de los oprimidos nos enseña que el "estado de emergencia" en el cual vivimos no es la excepción, sino la regla. (Benjamín, 2003: 392).

El capital es trabajo muerto que no sabe alimentarse, como los vampiros, salvo extrayendo trabajo vivo, y que vive más cuanto más trabajo vivo extrae. (Marx, 1867: 257).

\section{INTRODUCCIÓN}

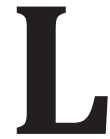

orena Estrada, una activista de los derechos humanos de los migrantes en la localidad de Cuautitlán-Izcalli, en el Estado de México, describió en una entrevista el proceso mediante el que los migrantes de Centroamérica, del sur de México y en algunos casos de Suramérica — muchas veces los más pobres de los pobres-, se transformaron en una significativa fuente de ingresos para las organizaciones del crimen organizado (Estrada, 2014). Durante décadas, los migrantes usaron los techos de los vagones de carga del tren-coloquialmente conocido como "La Bestia", - que pasa cerca de su casa en la estación de Lechería, en Cuautitlán-Izcalli. Muchos de sus familiares y vecinos salían rápidamente de sus casas hacia las vías del tren, cuando "La Bestia" pasaba, y aprovechaban la reducción de la velocidad para darles a los migrantes alimentos y bolsas de plástico llenas de agua. En esos años los y las inmigrantes no eran un asunto de interés para las organizaciones criminales, de repente se veía a la gente del Instituto Nacional de Migración(INM), pidiendo algunos sobornos a los migrantes en compañía de policías municipales, pero los carteles del crimen organizado se interesaban más en otros asuntos, como el secuestro de personas de clase media y alta, el narcotráfico y la trata de personas para la prostitución. En aquellos tiempos, los migrantes eran demasiado pobres para ser molestados. Una escritora, de origen mexicano, documenta esa visión en su libro,

1 La Bestia, es en realidad una red de trenes de carga que transportan diversas mercancías desde Tapachula (Chiapas) y Tenosique (Tabasco). Localidades ubicadas en la frontera sur de México (Guatemala) hasta la frontera norte (Estados Unidos). Paradójicamente es una red de trenes dedicados al transporte de "mercancías". 
Enrique's Journey (La Travesía de Enrique), cuando cita a un jefe de la policía municipal en Nuevo Laredo, quien "duda que aun sus oficiales corruptos tomarían a los migrantes pobres para robarles". Éste le dice, "cualquier persona inteligente buscaría alguien con más dinero, oro, cadenas, ropa" (Nazario, 2006: 149). Los migrantes entonces no eran un tema importante para el crimen organizado.

Pero con la llegada de la alternancia democrática en México en 2000, y la fortificación militar de la frontera con Estados Unidos - después del 11 de septiembre de 2001-, se empezó a gestar un profundo cambio en la visión que tenían los carteles del crimen organizado con relación a los migrantes y las mismas élites políticas. Algo muy delicado ocurrió a nivel de la estructura política entre los países de América del Norte, en los carteles de la droga ${ }^{2}$ y en la relación que se daba entre ambos. Ello movió todo el mapa delincuencial y generó múltiples tipos de vínculos entre diversos funcionarios públicos y políticos con representantes de los carteles del crimen organizado en México (Castillo, 2011). Los niveles de corrupción de los funcionarios del INM y de otras instituciones públicas como los tribunales de justicia y de las fuerzas policiales aumentaron notablemente, un cambio dramático estaba en marcha. ${ }^{3}$

En el año 2010, 76 migrantes de Centroamérica y Suramérica fueron secuestrados por el Cartel de los Zetas. ${ }^{4}$ El objetivo era cobrar rescates por ellos y ellas o reclutarlos en sus filas. Pero las víctimas no pudieron pagar el rescate y tampoco aceptaron ser reclutados por sus secuestradores, entonces los Zetas abrieron fuego contra ellas y 72 personas fueron asesinadas y enterradas en fosas comunes en San Fernando Tamaulipas. De ello no se sabría mucho sin las declaraciones de uno de los sobrevivientes. Un migrante ecuatoriano logró escapar de la matanza y pudo obtener el apoyo de miembros de la Marina de

2 En el año 2006, en los inicios del gobierno de Felipe Calderón, existían cuatro grandes carteles de narcotráfico: Los Carteles de Sinaloa, Juárez, el Golfo y la Familia Michoacana. Hoy en día existen por lo menos 7 carteles y 20 bandas locales. Los migrantes han sido una de sus principales fuentes de ingresos.

3. Para una mayor explicación se sugiere consultar el siguiente documento: El Estado de la Migración: México ante los recientes desafíos de la migración internacional. Telésforo RamírezGarcía y Manuel Ángel Castillo (Coordinadores). Consejo Nacional de Población (CONAPO). Ciudad de México. 2012.

4. Los Zetas son uno de los principales carteles criminales mexicanos. Surgieron a fines de la década de los noventas del siglo pasado y se expandieron por todo el territorio a los largo de la primera década del siglo XXI. Ellos fueron los que se interesaron en controlar y saquear a los migrantes que ingresaban por la frontera sur con Guatemala. Para una mayor información se sugiera revisar el artículo de Guillermo Valdés: El nacimiento de un ejército criminal. Nexos, 1 de septiembre del 2013. Dirección electrónica: http://www.nexos.com.mx/?p=15460. Fuente consultada el 12 de abril del 2015. 
Armada de México, fue él quien realizó las denuncias que permitieron conocer esta masacre (García, 2017).

El giro hacia los migrantes se dio dramáticamente. En los últimos 15 años, "La Bestia” se trasformó en un negocio perfecto para hacer dinero. Alrededor de ella se creó incluso toda una división social del trabajo delincuencial. Surgieron así: Operadores, halcones, administradores, sicarios. Toda una burocracia del crimen y sus víctimas: Los migrantes, de toda edad, género y grupo étnico. Las mujeres migrantes (la mayoría de ellas centroamericanas), por ejemplo, incluso inventaron una nueva definición para sus cuerpos. Los denominaron "cuerpomáticos", su tarjeta de crédito biológica para seguir avanzando en el trayecto hacía la frontera norte. Ante la ferocidad de los miembros de los carteles del crimen organizado, solo les ha quedado por ofrecer sus cuerpos como una mercancía sexual (Cruz, 2013). Las que no lo hacen sufren el robo de sus últimos recursos, o son secuestradas para pedirles a sus familiares al otro lado de la frontera el rescate respectivo. Al final de cuentas a lo largo del camino hay varias agencias de Western Union para cobrar las cuotas respectivas. Es el encuentro entre el capitalismo institucional y el capitalismo delincuencial ¿O estamos hablando de uno mismo? El que se niega o resiste es arrojado del tren en movimiento o asesinado a tiros para poner el ejemplo. La sentencia es muy sencilla, o pagas o mueres. El ticket del depósito al Wester Union significa la prolongación del sueño americano y su transformación en una perversa pesadilla. Pero a contracorriente de todo esto surgen los albergues para migrantes a lo largo de la ruta de "La Bestia". Ante ello, ciudadanos de a pie, la Iglesia Católica y sus curas recogen a los mutilados y han empezado a denunciar estas narco-políticas capitalistas, asimismo han surgido colectivos de la sociedad civil que se han movilizado y creado albergues a lo largo de la ruta del tren (Natera, 2015), sin embargo el resultado ha sido demoledor: Los más pobres de los pobres de la región (los y las migrantes) se transformaron en una pletórica fuente de ganancias para el crimen organizado y lo mejor de todo:

La impunidad para realizar este negocio estuvo y está garantizada por una extraña serie de coincidencias entre el estado y los criminales. Hay una relación implícita entre neoliberalismo, migración, ciudadanía y estado. Un proceso en dónde las vinculaciones políticas tejidas en torno al estado se difuminan y los derechos de las personas se mercantilizan o pierden sentido progresivamente. Aquí la democracia termina cerrándose en términos de estado de derecho para los migrantes (Luque, 2014). 
Junto con la comprensión de que aún los más pobres podían generar beneficios, se produjo otra innovación: Los carteles del crimen organizado comprendieron que los beneficios que podían extraer de los migrantes no se limitan a su trabajo, sino que estos se extiendan a sus propios cuerpos. La vida humana se transformó en una mercancía más sometida a los rigores de la oferta de los mercados (legales o ilegales) y se naturalizó la violencia ejercida por los carteles del crimen organizado contra migrantes indefensos. Ante ello toda posibilidad de recurrir al estado de derecho se diluyó en la catástrofe de los derechos humanos, en los miles de desaparecidos y en los que menos cuentan, porque no son contados y han sido abandonados por sus estados.

Básicamente, lo que estamos viendo hoy es un tipo de capitalismo comparable con otras variantes previas en su búsqueda amoral de la ganancia, pero que es innovador en el sentido que coloca al beneficio no solo en la expansión territorial de los mercados, o la minimización del trabajo y los costos de las materias primas, sino en los cuerpos de los pobres, para ello primero los despoja de su ciudadanía, privándolos de todos sus derechos, transformándolos así en objetos. Es un capitalismo sin límites, voraz, que succiona todo lo que puede y a quien puede, no sólo extrae la plusvalía del pobre, sino lo hace de todas sus redes sociales hasta dejarlas secas. A su paso deja estelas de mutilados y mutiladas, de desaparecidos y desparecidas. No importa la edad, género o condición étnica. No es menor que la Comisión Interamericana de Derechos Humanos (CIDH), en su informe del 2013: "Derechos humanos de los migrantes y otras personas en el contexto de la movilidad humana en México", calificó la situación de los migrantes como una catástrofe humanitaria. Las cifras exhibidas en los dos últimos años del gobierno del presidente Enrique Peña Nieto son contundentes: En el último periodo de gobierno se han contabilizado al menos 24 mil personas desaparecidas, cerca de 60 mil asesinatos y están pendientes de identificar, cerca de 25 mil restos humanos, según cifras de la Procuraduría General de la República (PGR) y la Comisión Nacional de Derechos Humanos (CNDH). Respecto al número de personas migrantes desaparecidas, el Comité de Familiares de Migrantes de El Salvador (COFAMIDE) registra al menos 350, el Foro Nacional para las Migraciones de Honduras (FONAMI) 600 casos, las organizaciones de Guatemala registran un número mínimo de 150 casos y en México, la CNDH ha reportado 20 mil secuestros de migrantes en un año. 
El capitalismo en el que se inserta el actual fenómeno migratorio en México es exitoso porque sus víctimas de hecho se mueven hacia él, lo buscan y participan voluntariamente en él; pero la seducción no hace falta-este cazará a sus víctimas-, si es necesario, en donde viven. En estricto sentido, los migrantes están en la primera línea y son los más vulnerables. Es en las depredaciones de los cuerpos de los migrantes dónde encontramos y vemos los más visibles y obvios-y no obstante menos lamentables - actos de este capitalismo voraz. Sin embargo, cada vez más, vemos que los pobres no necesitan migrar para convertirse en sus presas. Los pobres en las comunidades que han visto una reducción en la migración son todavía visitados por esta amenaza. Se teoriza que esta nueva forma de capitalismo voraz se abalanza de cuatro maneras sobre los migrantes: I) los despolitiza de sus derechos humanos y de ciudadanía; II) elimina los cuerpos sobrantes; III) Los recategoriza como una amenaza al estado y a la sociedad y por tanto los hace sujetos a la violencia o neutralización por parte de cualquier agente del estado o actores para-estatales, y; IV) finalmente, los presiona hacia el consumo y hacia el trabajo clandestino, lo cual a su vez, en su máxima expresión, disminuye casi totalmente las demandas que pueden hacer en el estado para hacer visible o denunciar sus condiciones de vida.

Hoy en día las poderosas elites capitalistas que apenas llegan al uno por ciento de la población tienen el control del 99 por ciento de los recursos (Stiglitz, 2012), son voraces, viven a expensas de la fuerza vital del resto de nosotros. Este tipo de capitalismo se tiene que explicar y describir en relación a su desarrollo en Latinoamérica. Para empezar, vamos a bosquejar una descripción preliminar de este capitalismo voraz y contextualizarla dentro de lo que vemos como la formación de un México post-migratorio, post-político y post-laboral (Gálvez 2018). Se propone que este capitalismo voraz, ofrece una metáfora para conceptualizar un sistema para la generación de beneficios estrictamente del consumo, y no de un sistema más amplio compuesto de las esferas del trabajo, los derechos, los recursos materiales y el consumo. Tal sistema maximiza sus beneficios mientras minimiza los costos, incluyendo las bases mínimas que el capitalismo tiene que proveer para la reproducción social y política de los trabajadores. 


\section{MONSTRUOS CREADOS POR EL CAPITALISMO}

No es de sorprender que la cultura popular y las narrativas se entremezclan con los cambios estructurales identificados por académicos. En 1995, justo un año después de la firma del Tratado de Libre Comercio de América del Norte (TLCAN), cabras y otros animales de granja en el norte de México fueron encontrados muertos, con marcas de mordidas en sus cuellos (Gallo, 2004: 287). En el año 2000, mientras realizaba una investigación en la región desértica del norte de Chile, se escuchaban algunos relatos sobre el Chupacabras, una mítica criatura a la que se culpaba por las muertes del ganado y seres humanos, los cuales habían sido encontrados muertos y sin sangre (Gálvez s.f.). Pero ¿Dónde eran encontrados? La mayor parte de evidencias sobre los Chupacabras fue encontrada en áreas asociadas con la industria minera del Norte Grande de Chile. La riqueza de Chile durante el último siglo y medio anterior ha sido principalmente extraída de la región desértica del norte, la mayor parte del tiempo por las firmas mineras inglesas, estadounidenses y canadienses. Las características espaciales de este régimen de extracción están caracterizadas por la extrema desolación y sequedad del desierto de Atacama, el más seco del mundo, marcado por operaciones mineras actuales y obsoletas - los asentamientos mineros de nitrato abandonados-, que se asemejan a pueblos fantasma. Los trabajadores mineros viven en ciudades costeras como Arica, Iquique y Antofagasta y son transportados en autobuses para laborar en jornadas de una semana de duración en las desérticas zonas montañosas. Generalmente viajan antes del anochecer, lo que hizo que estos obreros, fueran el blanco del Chupacabras. En un contexto dónde abandonan sus hogares y familias, para realizar un trabajo sin futuro, mal pagado y sin ningún tipo de derechos laborales.

Hay ciertos paralelos que se pueden trazar entre los Chupacabras de la región minera de Chile y los demonios andinos de las crónicas de Taussig (1980) para las minas de Bolivia. Ambas son metáforas para comprender este capitalismo. El Chupacabras fue visto en varios de los países del continente a finales de la última década del siglo pasado y los primeros años de este siglo. En la Ciudad de México, creativos vendedores de la calle junto con los caricaturistas políticos de la época, fusionaron la crisis económica del país con el Chupacabras, para ello colocaron la cabeza del entonces presidente Carlos Salinas de Gortari en el cuerpo del animal, surgiendo una imagen que 
representaba al naciente neoliberalismo mexicano con las tradiciones populares, la figura del nuevo Chupacabras político fue estampados en camisetas, reproducido en alebrijes y piñatas, otros lo dibujaron como un vampiro. Surgieron, asimismo, diversos juegos de palabras para referirse a Salinas de Gortari, algunos lo describían como un chupadólares o dollar sucker un autor mexicano describe este proceso:

Aunque los lectores podrían estar tentados a desestimarlo como un vuelo de fantasía barroca, el mito de Salinas como el Chupacabras, despliega una serie de estrategias simbólicas, extremadamente complejas, incluyendo los procesos de condensación, desplazamiento y colocación que Freud atribuyó a las labores del inconsciente (Gallo, 2004: 287).

Actualmente, vemos contornos similares en la obsesión de la cultura popular con los zombies, usualmente personajes ubicados en lugares distópicos post-apocalípticos, donde la gente tiene que reinventar a las comunidades de los vivos, comúnmente mediante el re-aprendizaje de muchas artes de caza y recolecta, agricultura, y sistemas de vigilancia. La distopía está cada vez más caracterizada como una nueva tierra post-mercado donde las relaciones humanas están reducidas a lo más elemental.

Podemos ver en estos mitos la expresión simbólica de fuerzas del mercado hipertrofiadas y voraces que amenazan las interacciones y actividades humanas mundanas. En respuesta a ellas, vemos un esfuerzo de seres humanos ordinarios y mortales que reclaman espacios sociales y físicos para su uso y la producción de la agencia colectiva e individual. En ello está en juego la posibilidad de la politización frente a la despolitización, del ciudadano frente al consumidor, del ciudadano al no-ciudadano.

\section{LA LÓGICA CAPITALISTA VORAZ: ¿DESAPARICIÓN? MigRACIÓN Y TLCAN}

La llave del grifo se cerró entre los años 2008 y 2010. En aquel período la migración neta de México alcanzó una tasa de crecimiento del 0.0 por ciento en el año 2012. (Castañeda y Massey, 2012; Passel, D’vera y González-Barrera, 2012). En ese momento un número ligeramente mayor de personas migró a México desde los Estados Unidos que hacia los Estados Unidos desde México. Las opiniones difieren sobre las causas: unas afirman que ello se debió a una mayor seguridad de la frontera y un mayor riesgo asociado con el cruce; otra argumentaba 
sobre la existencia de mayores oportunidades económicas en México; otra explicación señalaba que esto correspondió con la frustración de los migrantes debido a la incapacidad del presidente Obama por cristalizar una reforma migratoria en los Estados Unidos. Es claro que la migración mexicana ya no es un flujo unidireccional, y algunos han avizorado que no regresará a sus altos niveles históricos. (O'Neill, 2012). Entonces, si seguimos la lógica de los datos y México se encuentra ahora en una era post-migratoria, es conveniente preguntarse acerca de los factores de expulsión que promovieron la migración en el pasado -entre ellos la pobreza, principalmente- $i$ Estos fueron solucionados o no? Actualmente, la pobreza no ha aminorado, y los indicadores relevantes de la Comisión Económica para América Latina (CEPAL, 2015), señalan que está creciendo. La desigualdad no ha disminuido, y en muchos sentidos se ha incrementado, ello lo vemos en el número de millonarios en México que se ha ido incrementado y tomando mayores porciones de la riqueza de la nación México. (Kahn, 2013). Mientras que el salario mínimo es en efecto 18.5 por ciento menos de lo que era hace veinte años.

El Tratado de Libre Comercio de América del norte (TLCAN) inició en enero de 1994 con la promesa de transformar a México. En palabras del entonces presidente Carlos Salinas de Gortari: "(El convenio) avanza en sus objetivos: regular con claridad el creciente comercio entre nuestros países, alentar la inversión y la creación de empleo" (para regular claramente el creciente comercio entre los dos países; fortalecer la inversión; y crear empleos.) Salinas dijo que: traería un fin a la pobreza, a la migración y empezaría "la gran época del campo mexicano" (the golden age of the Mexican countryside) (Flores, 2014). La transformación del campo mexicano fue anticipada, por los funcionarios presentes en la negociación, quienes revelaron que 500 mil campesinos abandonarían la agricultura de subsistencia y otras ocupaciones rurales por empleos en la manufactura. La realidad fue mucho más dura, medio millón de personas por año en la década siguiente migraron a Estados Unidos y muchos más fueron desplazados a las ciudades y en el mismo campo - pues las tierras quedaron improductivas debido a la falta de cultivos, irrigación, y lluvias-. A pesar del plan para transformar el campo y reubicar la productividad, el movimiento transnacional de trabajadores no fue incluido para ser negociado. Luis Ernesto Derbez (2006), diplomático y político mexicano y que fue parte de las negociaciones y más tarde Ministro de 
Relaciones Exteriores de México, dijo que la regulación de la migración fue un tema imposible de ser incluido en las pláticas del TLCAN. México acordó excluirlo de la mesa de negociación para evitar la desintegración completa del acuerdo comercial. Como tal, lo que México podría haber concebido como una banca de tres patas (liberalización de los flujos de bienes, capital y trabajadores), se convirtió en una banca de dos patas y muy inestable. Las consecuencias fueron desiguales, por un lado, los bienes y capitales circularon a una velocidad y facilidad sin precedentes, mientras que los trabajadores se vieron obligados a buscar trabajo fuera de sus localidades, soportando la carga de la ilegalidad al tiempo que se iban. Con el TLCAN, el escenario quedo listo para una transformación de la economía mexicana que destruiría muchas estrategias de subsistencia de las familias rurales, mientras no les permitía moverse libremente en búsqueda de oportunidades económicas. Las consecuencias incluían el acceso y el trabajo ilícitos de los migrantes mexicanos en los Estados Unidos y el estancamiento de las actividades productivas en las comunidades rurales de origen.

La migración permitió la maximización del beneficio en dos formas: la migración de los managers a los lugares de producción donde los trabajadores locales pobres trabajan por menos, y la migración de trabajadores - como residentes despojados de sus derechos- a los sitios de producción en los cuales estos son deportables y explotables. Pero estamos viendo cada vez más que la migración está declinando en su importancia como estrategia económica. En su filme futurista de ciencia ficción Sleep Dealer (2008), el director Alex Rivera pinta una distopía post-migratoria donde la producción se transforma en un acto de performance. En vez de cruzar las fronteras, los trabajadores viajan a las maquiladoras locales donde literalmente se conectan a los servidores transnacionales cibernéticos y gestualizan el trabajo que está siendo realizado simultáneamente por robots humanoides en los Estados Unidos. La migración ha dejado de ser vista como un eje central al progreso económico estadounidense, y para el Gobierno de México la regularización de la población mexicana migrante no autorizada en los Estados Unidos ha sido reducida a una cuestión humanitaria y social, sin ser considerada realmente una cuestión económica (Medina Mora, 2014).

Justo antes de que el TLCAN entrara en vigor, el presidente de los Estados Unidos, Bill Clinton hablo a sus connacionales: 
No podemos detener el cambio global. No podemos revocar la competencia económica internacional que está en todas partes. Solo podemos emplear la energía para nuestro beneficio. Ahora debemos reconocer que la única forma que tiene una nación rica para crecer y hacerse más rica es exportar, encontrar simplemente nuevos clientes para los productos y servicios que ésta hace (1993).

Las afirmaciones de Clinton hoy en día son muy discutibles, pero el hecho es que en ese momento el capitalismo voraz fue desatado en México.

El libre comercio ha sido una idea habitualmente promovida por los economistas liberales, desde Adam Smith hasta Friedrich Hayek. Uno de los más importantes economistas de esta tendencia ha señalado la importancia de este argumento utilizando una frase del presidente John F. Kennedy: "una creciente ola está levantando todos los botes" (Friedman, 2012), sin embargo, los beneficios del libre comercio nunca han sido distribuidos igualmente, ni tampoco sus daños.

Históricamente, por supuesto, los pobres siempre han sido una fuente de ganancias, pero esto era principalmente por medio de su trabajo. La alienación del esfuerzo productivo de los trabajadores a un costo mínimo ha sido uno de los principios de explotación clave de los modos de producción capitalista y la fuerza impulsora detrás del colonialismo.

El colonialismo del imperio español (y el europeo) abrió nuevas fuentes de materias primas, trabajadores, y mercados pero se enfocó en mayor medida en la producción de bienes para su venta en los territorios metropolitanos ubicados en Europa, en ellos los consumidores accedían a los bienes y servicios facultados por su posición en la estructura social imperial, lo cual los colocaba en un lugar superior en la jerarquía del capital y el trabajo, mientras que el consumo entre los pobres era mínimo, y comúnmente regulado por las leyes suntuarias impuestas por la España borbónica en el nuevo mundo (por poner un ejemplo). La independencia buscó romper la relación asimétrica entre la colonia y el imperio, pero en los años siguientes, lo que le siguió fue una reproducción de los patrones previos. Dentro de los países de Latinoamérica y el Caribe, las dinámicas centroperiferia mantuvieron la riqueza concentrada en unas cuantas manos, mientras que los trabajadores pobres, ampliamente relegados a los márgenes del panorama nacional, permanecieron excluidos y en la miseria. Las corporaciones multinacionales, anteriormente asociadas 
con los poderes imperiales, empezaron a operar en el vacío, usando los gobiernos nacionales para crear políticas públicas y estructuras favorables para la inversión.

La ganancia se obtenía del consumo de los trabajadores - considérese las tiendas de raya de las compañías transnacionales en las economías de enclave- pero era una ventaja, subordinada a la tarea de suministrar las mercancías necesarias para cubrir las necesidades básicas de los trabajadores requeridas para su reproducción. Ya sea chocolate, cigarrillos y azúcar blanca en siglos pasados, o teléfonos inteligentes y zapatillas deportivas actualmente, mientras los países ricos y los pocos ricos dentro de los países pobres, eran los que se esperaba que consumieran los bienes producidos por los trabajadores pobres, incapaces aún de comprar lo que ellos producían.

Las desigualdades y dependencia producida por este tipo de arreglos fueron afrontadas de maneras nacionalistas a lo largo del siglo XX por gobiernos de izquierda, con los estados latinoamericanos trabajando para nacionalizar la explotación de los recursos naturales y la producción de las principales materias primas o sustituir las importaciones con modelos producidos localmente. Mientras tanto, la política de la Guerra Fría proporcionó un pretexto ideológico a las corporaciones estadounidenses para avanzar una revolución neocolonial y neoliberal en la región, usando al Fondo Monetario Internacional (FMI) y al Banco Mundial (BM), así como a otras instituciones financieras importantes y al gobierno de los Estados Unidos para promover el capitalismo de libre mercado y la democracia en la región, sancionar el ajuste estructural, levantar las barreras al comercio y hacer al mundo más seguro para la inversión. En los últimos veinte años, al tiempo que la sabiduría convencional ha promovido cada vez más la noción de Thatcher de que no hay alternativa (Bromund, 2013), los modelos políticos y económicos neoliberales basados en el mercado han llegado a dominar en muchos países en la región, salvo pocas excepciones.

Algunas de las ampliamente documentadas consecuencias de las reformas neoliberales en la región han sido los asaltos al movimiento sindical organizado tanto a nivel nacional como hemisféricos, la disolución de las redes de protección de seguridad social, y una masiva supresión de los gastos en la educación pública, el cuidado de la salud y la infraestructura. El resultado ha sido una reducción de las funciones del estado en la seguridad y una descomposición de los mecanismos de 
beneficio social con algunas de las más extremas infusiones de lógica de mercado en la vida pública, que se pueden ver en países que fueron expuestos a las transformaciones más impactantes (Klein, 2007): Chile, Perú, Guatemala, Honduras, El Salvador y, como empezamos a percatarnos, también México.

El crecimiento de la clase media global proclamada por organizaciones pro-comercio (Pezzini, 2014), es un proceso que deja entusiastamente atrás a la agricultura de pequeña y mediana escala, en nombre del progreso, la modernización, y el desarrollo. La monetización de los mercados y el intercambio de divisas en las comunidades más rurales han significado que el consumo está ahora globalizado. La expansión de los mercados se podría argumentar, es completa en cuanto a su alcance global, pero todavía emergente en términos del alcance a los consumidores. Los beneficios se pueden esperar que provengan de la creación de los consumidores aún más que de la diversificación de productos. Y con las tecnologías que alcanzan aún las más remotas comunidades — teléfonos inteligentes, internet, banca electrónica y más-, la distancia con los centros urbanos se hace irrelevante. De la misma manera lo es el poder de compra. El crédito al consumo, préstamo de efectivo, remesas, y la reconfiguración de la fuerza laboral han hecho de todos unos consumidores. No es necesario ganar como la clase media para consumir como ellos.

El TLCAN ha producido y aumentado la visibilidad de cuerpos sobrantes, aun cuando en coordinación con el plan general de desarrollo económico de México, ha preparado su desaparición en el largo plazo. La migración fue el instrumento de elección para tratar con el excedente de trabajadores durante la mayor parte del siglo XX en México. Mientras que el acuerdo comercial resultó en un aumento del flujo inicial de nueva migración, especialmente entre 1995 y 2005 , las cosas han cambiado desde entonces, al tiempo que la migración se ha hecho más estrecha, otras transformaciones se han originado. La tasa de fecundidad en México fue de 4.7 por ciento en 1980, y solo una generación después, 2.2 por ciento por mujer en 2013. (Banco Mundial, 2015). La política social —algunos la han llamado ingeniería social- busca promover familias más pequeñas en tamaño y mayores niveles de educación como una estrategia de largo plazo para reducir la pobreza. El programa anteriormente denominado Oportunidades, ahora llamado Próspera, es un muy discutido programa de incentivos monetarios que recompensa a familias, madres específicamente, 
por mantener sus niños en la escuela, usar anticonceptivos y asistir a las visitas de los coordinadores del programa. Sin embargo, el desplazamiento de las zonas rurales y el cambio en los sectores de crecimiento económico ha generado que la economía formal no haya absorbido suficientemente a los nacidos entre los años 1985 y 2000. Según el informe del año 2015: "Prosperidad compartida y erradicación de la pobreza en América Latina y el Caribe", financiado por el Banco Mundial, la pobreza en México no ha bajado desde el año 1992, por el contrario, ha aumentado. La cantidad de mexicanos en extrema pobreza - con un ingreso diario insuficiente para adquirir una canasta básica alimentaria- fue de 23.1 millones de personas, la cifra más alta desde 1988. En tanto, en la clasificación de pobreza moderada se encuentran 61.4 millones de mexicanos, el mayor número desde 1996 (Cord, Genoni y Rodríguez-Castelán, 2015). Todos ellos no han continuado con la migración, pero tampoco han sido incorporados en la economía. La crisis es especialmente aguda en el campo donde antiguas formas de marginación persisten, tales como la discriminación sistemática en contra de las comunidades indígenas, infraestructuras en salud, educación, vivienda, drenajes y caminos muy pobres, además del narcotráfico, la violencia derivada del mismo y el surgimiento de narco economías locales dedicadas al cultivo de marihuana y amapola (este último un insumo esencial para la producción de la heroína).

Como resultado, tenemos lo que algunos han llamado ajustes a la transición económica y demográfica (Rojas-Suarez, 2009). Al tiempo que México ha cambiado de una economía rural a una economía manufacturera y de servicios, se observa que las poblaciones dejadas de lado o excluidas de este proceso están a la expectativa (O’Neill, 2014). Pero cada vez más, las recompensas prometidas de los trastornos económicos y sociales no están alcanzando a aquellos que han sido desplazados violentamente. Sin haber entrado a la clase media, su consumo - aun de los elementos más básicos de vida: comida, agua, educación, cuidado de la salud y servicios - es comercializado y privatizado, por las corporaciones multinacionales mejor ubicadas para acumular las ganancias. La pregunta pertinente es ¿Cómo hacen los pobres para comer, consumir y no trabajar del todo? Una respuesta posible es el mercado laboral del crimen organizado. 


\section{RECATEGorizaCión: AYOTZINAPA Y LA POST-POLÍTICA}

El 26 de septiembre de 2014, 43 estudiantes de la Escuela Normal Rural, Raúl Isidro Burgos de Ayotzinapa, que realizaban actos de propaganda y recolectaban dinero en distintas localidades y caminos del estado de Guerrero para asistir a las Jornadas Conmemorativas por la masacre de estudiantes el 2 de octubre de 1968 en la Plaza de las Tres Culturas de Tlatelolco, Ciudad de México. En ese contexto, fueron agredidos y detenidos por la policía municipal de Iguala, y luego entregados a miembros del cartel criminal "Guerreros Unidos" por órdenes del Presidente Municipal de Iguala (alcalde), José Luis Abarca, militante en esos momentos del Partido de La Revolución Democrática (PRD) y además un prominente dirigente de dicho cartel criminal. Los estudiantes de Ayotzinapa fueron detenidos ante la mirada de miembros del Ejército y Policías Federales. Ante la inacción del estado, los familiares de los 43 estudiantes se movilizaron apoyados por organizaciones de derechos humanos. En su búsqueda encontraron decenas de fosas comunes repletas de cadáveres, el horroroso descubrimiento de estas fosas comunes en la región abrió la caja de Pandora del horror generado por las relaciones de impunidad articuladas entre los poderes políticos locales y estatales con el crimen organizado. Más tarde, el entonces Procurador General de la República, José Murillo Karam, anunció lo que llamó la "verdad histórica" del caso: Miembros de "Guerreros Unidos", revelaron que los estudiantes habían sido torturados hasta la muerte, posteriormente, los cadáveres fueron apilados y quemados en una hoguera que duro más de 12 horas, finalmente las cenizas fueron recogidas en bolsas de basura y lanzadas a un rio. Mientras tanto, lo familiares continuaron la búsqueda, y más fosas clandestinas han sido encontradas, en tanto las familias siguen demandando el regreso de sus hijos vivos como se los llevaron, y miles de estudiantes y ciudadanos han participado en decenas de protestas a lo largo de México. La revelación de lazos entre el estado y los narcotraficantes y la violencia extrema en contra de los estudiantes ha convulsionado a México y al mundo.

Los estudiantes de la Normal Superior de Educación Raúl Isidro Burgos de Ayotzinapa, un colegio de profesores de sexo masculino, pertenecen en su mayoría a comunidades indígenas y rurales de la región mixteca de Guerrero, una región marcada por las altas tasas de marginación y pobreza, y hasta recientemente, altos niveles de 
migración. También es un corredor para el tráfico de drogas y el estado de Guerrero, cuenta con la concentración más alta de cultivos de opio y amapola.

Los estudiantes se estaban preparando para regresar a enseñar en sus propias comunidades o en otras vecinas. En la superficie, porque ellos eran estudiantes y no migrantes, representaban una victoria en las trasformaciones económicas y sociales de México, de la cual la política comercial y el TLCAN es una pieza singular. Una de las metas explicitas del estado mexicano fue apuntalar el crecimiento de la economía y reducir la población lo suficiente para que el trabajo alcanzara para todos. La migración debió también reducirse debido a esa dinámica esperada, al absorber la economía local a los trabajadores en los nuevos sectores económicos de la manufactura, los servicios y la tecnología. Pero: "entre lo dicho y lo hecho, hay mucho trecho"; es decir, hay un largo tramo entre lo que se dijo al firmar el TLCAN y lo que se hizo finalmente. Y los estudiantes de Ayotzinapa estaban viviendo en ese trecho,- - en el intervalo entre la permanente promesa de la futura economía, y una realidad en donde lo más viejo de México se encontró con lo nuevo del neoliberalismo- y finalmente, este intervalo al menos para los 43 estudiantes fue cerrado violentamente.

La Normal Raúl Isidro Burgos de Ayotzinapa tiene la reputación de ser una escuela fervientemente marxista. Se trata de una universidad latinoamericana que se ubica en la tradición de la protesta. Sus paredes están cubiertas con murales del Che Guevara y el subcomandante Marcos. Sus estudiantes cierran avenidas como forma de protesta, $\mathrm{y}$ a menudo, toman autobuses locales y ofrecen a los conductores - quienes de acuerdo con algunos periodistas se han acostumbrado a esta situación-, una pequeña cantidad de dinero para esperar el retorno del autobús horas más tarde. Eso fue lo que estaban haciendo el día 26 de septiembre en Iguala, pero terminaron desaparecidos. Los estudiantes desaparecidos y las numerosas fosas clandestinas indican que hay un patrón de desaparición de personas en esa región (la evidencia además muestra que Guerrero no es un caso aislado, tenemos fosas comunes en Tamaulipas, Michoacán, Veracruz y Jalisco). En esta violenta, incluso destrucción caníbalesca de los cuerpos de los pobres, quienes se resisten al consumo y monetización de la vida social son recategorizados como criminales, y/o destruidos. Ayotzinapa es una sangrienta, penosa y escandalosa revelación de una tendencia mayor en curso. Aquellos que no se ajustan, que no pueden ser absorbidos en 
la economía y que no migran, y quizá más importante, que rechazan los nuevos roles asignados, deben ser desaparecidos.

El espectáculo de los estudiantes desaparecidos es horroroso, pero la evidencia inicial indica que ni siquiera la escala de este hecho es novedosa. En un artículo muy completo sobre incidentes en Iguala, el escritor Francisco Goldman señaló que Calderón (presidente de 2006 a 2012) comenzó una guerra con los carteles, una guerra continuada por el expresidente Peña Nieto, que convirtió a todo México en una narco-fosa. La filtración de cuerpos que se muestran todos los días en las noticias en México desde el 2006 es escalofriante y genera indignación, dolor, miedo y enojo. La "narcomáquina", como Rosanna Reguillo (2011) la llama, ha evolucionado a nuevos niveles. Sus vínculos con el estado se han hecho más visibles y evidentes. Si Iguala no fue el primero ni el peor caso, ¿Por qué ahora? ¿Por qué este incidente? ¿Fue casual que esta noticia lleguará en un momento en el que Peña Nieto está finalizando sus esfuerzos para reformar radicalmente la educación, las telecomunicaciones y la energía en México?

Si aceptamos que el estado y la narco-máquina están trabajando en coordinación, debemos preguntarnos ¿Para qué fin? Seguramente, deben ser "malas manzanas": funcionarios electos y agentes del orden público, periféricos, que son granujas y corruptos, y que se involucran en tratos oscuros con los jefes locales del narco involucrando espacios políticos, recursos y personas locales. En lugares donde la violencia está peor, es porque la narco-máquina esta tan fuera de control que nadie puede combatirla sosteniblemente y sobrevivir. Estas son las excusas dadas, previo a Ayotzinapa. Incluso, esta perspectiva es productiva porque le permite al estado legítimamente reforzar su propia violencia, invirtiendo en armas más elaboradas y caras y maniobrando para destruir el liderazgo del cartel y perturbar sus operaciones. Pero actualmente, es claro, si todo México es una narcofosa, que el problema es más profundo que eso y más pernicioso.

El entrelazamiento del estado con el crimen organizado y las funciones extra-estatales que estos han adquirido como el cobro de impuestos a pequeños y medianos comerciantes, se exacerba en la reducción en cuanto a cuerpos sobrantes, ya que en sus dos principales formas están alineadas con la mayor reorganización de la economía mexicana y de México en su conjunto. Primero, las narco-fosas. Ellas hablan de desapariciones masivas en amplia escala de grandes números de mexicanos y también de no-mexicanos. La desaparición 
explicita de estudiantes mientras protestaban es más parecida a una revelación de una estrategia de larga data, una corrida del velo, más que una desviación en los métodos. Si la pobreza no ha sido reducida y la migración si, México está enfrentado a una situación potencialmente incendiaria. Enfocarse en gente joven como blanco para la violencia, la misma gente joven convertida en superflua por el cambio en la economía, envía el mensaje de que ellos no deben salirse del carro del progreso neoliberal o serán arrollados por éste.

En segundo lugar, la actual guerra contra las drogas permite al estado criminalizar y por ende atacar constantemente a cualquiera que está vinculado con la narco-máquina. Según el antropólogo Francisco Mancha en el año 2011, jóvenes de la región del centro de México fueron enviados no acompañados a los Estados Unidos por sus familias ante el temor de que fueran reclutados por la máquina-narco como mulas o asesinos. Actualmente, unos años después, ellos siguen migrando en menor escala desde esa región, - ya que la migración ahora es menos un método para evadir la narco-máquina sino que una entrega a la misma- los jóvenes continúan tratando de hacer su vida en medio de una violencia intensificada (Mancha, 2011). Aquellos que son asociados de alguna manera -incluso por adoptar las preferencias de vestimenta de los narcos que han llegado a dominar en muchas regiones de México-, son perseguidos como criminales. Un prominente escritor mexicano, Juan Villoro ha dicho que México está al borde de un estallido social si continúa criminalizando a los jóvenes, en lugar de brindarles oportunidades (Mandujano, 2014). Pero esta probable explosión social puede ser evitada si suficientes jóvenes son criminalizados. Las mismas contradicciones del sistema son contundentes: Demasiados jóvenes para muy pocos puestos de trabajo; el rechazo de estos jóvenes a las orientaciones mercado céntricas; la creciente importancia de las narco-economías en sus vidas y el paulatino desencanto en la democracia. Estamos al borde del límite, por eso los jóvenes de Ayotzinapa incautaban autobuses públicos y lanzaban bombas molotov, lo político se había vuelto inaudible, corrupto, imposible de ser reconocido. Finalmente, ellos fueron y siguen siendo silenciados, ya sea como víctimas de "Guerreros Unidos" o como infractores de la ley aniquilados por el ejército en Tlatlaya, Estado de México (Zepeda, 2014), eso es lo relevante. 


\section{Consumo / Posesión}

Debord escribió que, en la etapa primitiva de la acumulación capitalista, el trabajador necesita solamente "ser asignado el mínimo indispensable para mantener su fuerza de trabajo ", pero eventualmente,

La abundancia de los productos alcanza un nivel que requiere una colaboración adicional de él... Una vez que termina su jornada de trabajo, el trabajador de repente es redimido del total desprecio hacia él que está claramente implícito en cada aspecto de la organización y vigilancia de la producción y se encuentra asimismo repentinamente tratado como un adulto, con una gran muestra de cortesía en su nuevo rol como consumidor (Debord, 1967: 43).

El más sutil, pero en muchos aspectos el método más desarrollado para tratar con los cuerpos sobrantes es distraerlos, debilitarlos o enfermarlos de tal manera que se rindan incapaces o renuentes a participar en la economía, la política y la protesta social. Muchos criticaron la elección del expresidente Enrique Peña Nieto, cuyos vínculos con los medios de comunicación y su apariencia telegénica a muchos les pareció como falsa. Las irregularidades en la campaña y las votaciones, tales como la distribución de regalos a los votantes, tarjetas para las cadenas de supermercados, sólo acentuaron esa percepción. Pero Debord argumenta que el espectáculo provee cobertura para la violencia creciente del Estado. En el mismo período post-TLCAN, el sistema alimentario de México ha sido completamente modificado, resultando en un incremento exorbitante de enfermedades relacionadas con la dieta y la obesidad, por los cuales México es ahora el número uno en el mundo. Las tasas de síndrome metabólico, la diabetes y las enfermedades del corazón están en aumento. Al mismo tiempo, el cuidado de la salud se ha transformado en formas que simultáneamente disminuyen el financiamiento al sistema de salud público en general, mientras que convierten la estructura general de cuidado de la salud a las lógicas de mercado (Gálvez, 2011).

Dentro de la reestructuración neoliberal de los mercados y del sistema de salud (que podemos ver reflejado en otros ámbitos, como la educación), el ciudadano-consumidor tiene el derecho de elegir el cuidado de la salud, basado en las alternativas que le ofrece el mercado. Maldonado, en su reciente tesis doctoral en antropología en la Universidad Brown, estudió el surgimiento de clases de yoga subsidiadas por el gobierno en la Ciudad de México, como un ejemplo 
de esta tendencia. A falta de cobertura médica formal y de ingresos suficientes para acceder a mejores opciones de cuidado de la salud, muchos ciudadanos pobres y de clase media baja han adoptado por el yoga como una forma de cuidarse a sí mismos. Observó que incluso algunas veces con condiciones médicas avanzadas y no tratadas, los practicantes de yoga enmarcaron su propia enfermedad como un fracaso para involucrarse totalmente en prácticas alternativas de curación, muy seguido no asistían a clases o no estaban tan concentrados y atentos como debería ser para alcanzar el máximo beneficio de salud y tranquilidad prometidos.

Analistas de prevención de riesgos lamentan los costos excesivos que implica una fuerza laboral enferma, pero sobretodo el problema ha sido catalogado por el gobierno y la mayoría de las principales fundaciones de salud como un problema de cultura y falta de educación. Dentro de esta rúbrica, ciudadanos pobres, sin educación y poco confiables deben asumir una mayor responsabilidad por su salud, en lugar de consumir comida chatarra en exceso y refrescos, o llevar una vida sedentaria. Ignoradas son las estrategias conspiradoras que quitan el aliento de que las empresas alimenticias han utilizado a México para dominar el suministro de alimentos a los niños en las escuelas, aumentar el consumo de refrescos, crear mercados para sus marcas, y promover la "supermercadización" (Bruce, 2006: 163174 y Reardon y Berdegué, 2000: 371-388). Y, dicho de otra manera: cambiar los patrones de consumo en formas que están, literalmente, enfermando a los mexicanos.

Uno de los principales cambios en la forma que México se alimenta es consecuencia directa del TLCAN y el abandono de la agricultura de subsistencia hacia un énfasis en la seguridad alimentaria. Mientras que, intuitivamente, la seguridad alimentaria podría parecer implicar la autosuficiencia alimentaria, o la capacidad de una nación para satisfacer las necesidades alimentarias de su población, la seguridad alimentaria es en realidad un principio basado en el mercado. Ésta implica la capacidad de la nación para satisfacer las necesidades alimentarias de su población, pero sin adjudicar ningún valor acerca de si satisfacer esas necesidades es el resultado de la importación de alimentos o de producirlos. De hecho, un país que no produce alimentos en absoluto puede estar mayormente en seguridad alimentaria simplemente por tener los medios económicos y los canales de distribución para la compra de toda su comida en el mercado global. La producción 
agrícola de un país puede declinar indefinidamente, siempre y cuando su poder adquisitivo aumente correspondientemente (Gálvez 2018). Las estrategias pasadas para garantizar la seguridad alimentaria, tales como la subvención o la fijación de límites a los precios de alimentos básicos, como el maíz y la leche en México, han llegado a ser prohibidos en el modelo centrado en el mercado para el desarrollo económico y la integración que domina actualmente. El énfasis en la seguridad alimentaria en México se ha traducido en que México ahora importa el 42 por ciento de los alimentos que consume, y que su producción agrícola es destinada principalmente a la exportación, pero no incluye alimentos de subsistencia, sino que produce alimentos especiales como fresas, tomates, aguacates y limones (Wise, 2014). De hecho, para México cultivar alimentos básicos es cada vez más visto como ilógico y poco eficaz porque los Estados Unidos con sus granjas industriales en gran escala, de utilización intensiva de capital, pueden cultivar más que suficiente para ambos países. Junto con este cambio hacia un énfasis en la seguridad alimentaria surge una necesidad por la expansión de los mercados. De este modo, vemos lo que Reardon (2002), anteriormente denominaba como supermercadización, la expansión de los supermercados de las grandes ciudades a los pueblos más y más pequeños, facilitado por los avances tecnológicos en el transporte marítimo y terrestre, los automóviles y la refrigeración. El aumento de los ingresos, la mercadotecnia y las aspiraciones a consumir de diferentes maneras pueden contribuir a este proceso. La inversión directa de los Estados Unidos en la industria de alimentos y bebidas en México creció de 2.3 mil millones de dólares en 1994 a 8.8 mil millones dólares en 1998, y los granos, el aceite y la carne representaron el 75 por ciento de las exportaciones agrícolas de Estados Unidos a México (Freudenberg, 2014: 156).

En el México rural, el proceso de acudir a los supermercados para los alimentos básicos es propiciado significativamente por un mayor acceso al dinero en efectivo. Dos fuentes importantes de dinero en efectivo son las remesas de los migrantes y las transferencias monetarias condicionadas. Las remesas de los migrantes hacia principios de este siglo llegaron a los 20 mil millones de dólares por año a México, principalmente en las comunidades rurales que expulsan migrantes. Las transferencias monetarias condicionadas, por ejemplo, como parte del programa Oportunidades, previamente denominado Progresa, ahora programa Prospera, son un tipo de asistencia social 
otorgada a los pobres por el Estado. El programa, creado en 1997, otorga pagos en efectivo directamente a las madres a cambio de participar en ciertos actividades propias de la clase media: llevar a los niños a vacunar y a chequeos médicos, mantener a los niños (especialmente a las hijas) en la escuela, participar en talleres de planificación familiar, practicar la anticoncepción, e incluso incide en el voto de los usuarios y usuarias del programa. La ingeniería social que subyace en estos programas recompensa a las familias más pequeñas que alientan a sus niños a estudiar, en lugar de sacarlos de la escuela para que realicen tareas domésticas o agrícolas, asimismo es un mecanismo de control político en dónde se premia la lealtad del usuario. Como lo vimos anteriormente, las tasas de natalidad son mucho más bajas hoy que al inicio del programa. Pero, ya sea que la migración, o la planificación familiar y la educación, son las que están reduciendo el tamaño de la familia rural y el número de trabajadores disponibles para el trabajo agrícola, el efecto es el mismo: la agricultura de pequeña escala ya no es viable. Con la modificación de la Constitución mexicana en 1992, que permitió la venta de ejidos colectivos, muchas pequeñas parcelas se han incorporado a grandes conglomerados agroindustriales, mientras que otros permanecen sin usar. Pero, debido a la disminución de la agricultura de subsistencia, las familias deben ahora acudir al mercado, cada vez más al supermercado, para satisfacer sus necesidades diarias de comida, y tienen el dinero para hacerlo.

Al considerar la gran expansión de las ventas de alimentos empaquetados y procesad os como una oportunidad de negocio, astutos empresarios mexicanos unieron sus fuerzas con las corporaciones extranjeras multinacionales para comercializar y vender a nuevos clientes. ConMéxico, una empresa de cabildeo dedicada al desarrollo de la industria de bienes de consumo trabaja incansablemente para asegurar un clima favorable para los negocios en México. Sus esfuerzos son extraordinariamente creativos: incluso lograron atraer a su empresa a Salomon Chetorivski, hijo del fundador de ConMéxico, nombrado Secretario de Salud de 2011 a 2012, con sólo un grado de maestría en Economía y otro en Política Pública, pero no con un título de médico. De este modo, observamos no sólo a las instituciones gubernamentales, encargadas de la política económica, promoviendo soluciones de mercado a problemas sociales y de salud, sino incluso al secretario de salud argumentando a favor de la capacidad de las empresas para autorregularse. 
En su libro "Letal pero Legal" (Lethal but Legal), el académico de salud pública de la escuela CUNY, Nicholas Freudenberg, documenta las formas en que las empresas estadounidenses se han involucrado en un esfuerzo concertado para promover el hiperconsumo a través de lo que él denomina el "complejo de consumo corporativo", "una red de empresas, instituciones financieras, bancos, asociaciones comerciales, de publicidad, cabildeo y despachos de abogados, y otros" (Freudenberg, 2014, xi). Yo argumentaría que este complejo ha sido facilitado en su expansión multinacional a través de acuerdos comerciales como el TLCAN, y pronto con el Acuerdo Transpacífico de Cooperación Económica (TPP), así como por partidos gobernantes pro-empresariales, neoliberales en México, que le han permitido interponerse en conversaciones locales acerca de la política económica, la salud pública y el consumo. Podemos explorar en México una reorganización completa del sistema de salud pública hacia uno basado en el estilo de vida, la elección, la educación y la responsabilidad, eufemismos para un proceso que ha desmantelado el sistema de salud pública y que ha re-direccionado funciones básicas de subsistencia hacia alimentos y bebidas procesadas, productos farmacéuticos, y otros productos, y lejos de la agricultura local.

Los factores estructurales que contribuyen al aumento de las tasas de consumo de refrescos y comida chatarra son ignorados en gran medida. Actualmente, la salud es presentada como un asunto que se encuentra en las manos de los individuos y las familias. Las enfermedades relacionadas con la dieta se presentan como un fracaso moral -un rechazo o incapacidad de cuidarse adecuadamente a uno mismo atribuido a la falta de educación y cultura. Estos son viejos argumentos que durante mucho tiempo han sido utilizados para justificar la marginación de los indígenas y pobres de México. La transformación casi total de las condiciones de vida caracterizadas por la migración de lo rural a lo urbano y transnacional, familias más pequeñas, menor agricultura en pequeña escala, la importación y compra en lugar de la producción de alimentos, y más, son ignorados y la carga de la preocupación por la salud y la prosperidad de los ciudadanos es retirada del estado y colocada sobre las espaldas de las familias.

Por consiguiente, aspectos de la vida que no están dirigidos por el mercado en una economía de subsistencia sucumben a su lógica: producción, procesamiento y adquisición de alimentos, crecientes 
esferas de ventas y mercadotecnia; y en seguida, para hacer frente a los resultados lógicos del hiperconsumo, tenemos a las industrias acompañantes enfocadas en la pérdida de peso, el bienestar y todos los gastos asociados con enfermedades crónicas: medicamentos, dispositivos médicos, registros y el cuidado. La idea de la buena ciudadanía está más que nunca estrechamente asociada con el buen consumo, con ideas sobre la inserción en el mercado que cada vez más sirven como representantes de otros tipos de asimilación y, su opuesto, la marginación. Por lo tanto, el estado está menos preocupado con demostrar que está enfrentando la pobreza, proveyendo oportunidades de educación y trabajo, de atención a la salud y otros servicios sociales, y más preocupado por expandir la participación del mercado. De hecho, algunos aspectos básicos de gobernanza están obligados a ser reformados y privatizados como reciprocidad (toma y daca) por la participación en los pactos comerciales los cuales demandan un acuerdo al comercio minimalista, protecciones laborales, ambientales y de salud ocupacional.

\section{Conclusión}

En las páginas anteriores, hemos representado una transición íntegra de la función del estado desde una amplia provisión de servicios sociales hacia una mínima provisión de seguridad y condiciones de mercado favorables, en las cuales aquellos que permanecen obstinadamente pobres o marginados, incluyendo los indígenas, estudiantes, familias grandes, y aquellos que objetan el modelo de consumo como ciudadanía son cooptados hacia el mercado, o desaparecidos de la vista vía re-categorización o destrucción. El consumo es facilitado y promovido a través de la privatización de los servicios, y aun a través transferencias directas de dinero en efectivo, al mismo tiempo que estrategias de subsistencia que incluyen el trueque, la producción agrícola de pequeña escala, y la compra a productores locales, se han vuelto obsoletas. El resultado, es una ciudadanía de baja intensidad, una ciudadanía menos política, más pobre, menos móvil y menos saludable, que paradójicamente está más ampliamente incorporada a la noción definida como un mercado, y menos incorporada como ciudadanos conferidos de derechos.

En estas formas, el modelo de capitalismo promovido por las políticas y programas neoliberales se basa en la premisa de la participación del mercado, principalmente en la forma de consumo. Al 
tiempo que las necesidades básicas de la vida son producidas cada vez más en contextos industriales altamente dependientes de la tecnología con cada vez menos necesidades laborales, y el ideal de ventaja competitiva y seguridad alimentaria subcontratan la subsistencia de lugares que hace una generación eran casi totalmente auto-suficientes, el único rol que se le deja a muchos mexicanos es como consumidores. La migración ha dejado de ser un medio viable para el ascenso social, en lugar de ello los migrantes se han vuelto vulnerables a la delincuencia organizada. Los empleos prometidos de alta tecnología y alta calificación han arribado, para unos cuantos afortunados, quienes pueden acceder a salarios de media clase y viven en centros urbanos. Pero para la vasta mayoría, cuyas familias siguen siendo demasiado grandes, y sus necesidades no cubiertas, la recategorización como criminales es un medio útil para silenciar sus demandas. De esta manera, ellos pueden ser desaparecidos o asesinados, aliviando la presión social y económica sobre las élites, y sirviendo para silenciar a otros. De esta manera, los estudiantes desaparecidos de Ayotzinapa no son una aberración o una excepción, sino una ilustración aterradora y horrorosa de un nuevo orden post-político. Un orden en el que la vida literalmente no vale nada.

En ambas ciudades (París y Londres) había corredores de bolsa, negociadores, y hombres de negocios, que succionaban la sangre de las personas en plena luz del día; pero ellos no estaban muertos, aunque si corrompidos. Estos auténticos vampiros no vivían en los cementerios, sino en palacios muy agradables. -Voltaire, Philosophical Dictionary.

\section{REFERENCIAS BIBLIOGRÁFICAS}

Banco Mundial. (2015). Datos. Tasa de fertilidad, total (nacimientos por cada mujer). Portal Electrónico del Banco Mundial. Consultado el 12 de abril del 2014 en http://datos.bancomundial.org/indicador/SP.DYN. TFRT.IN

Benjamín, Walter. (2003). Selected Writings 1938-1940. Cambridge: Harvard University Press.

Bromund, Ted. (2013). Margaret Thatcher her impact and legacy in global development, The Guardian. Consultado el 24 de marzo del 2015 en http:// www.theguardian.com/global-development/poverty-matters/2013/ apr/16/margaret-thatcher-impact-legacy-development 
Castañeda, Jorge y Massey, Douglas. (2012). "Do-It-Yourself Immigration Reform". (Ed.). The New York Times, June 2, 2012. Consultado el3 de enero del 2015 en http://www.nytimes.com/2012/06/02/opinion/do-ityourself-immigration-reform.html?_r=0

Castillo, Gustavo. (2011). "Controlan Zetas y cártel de Sinaloa la mayor parte del país: Siedo". La Jornada. 9 de Noviembre del 2011. Consultado el 3 de Mayo del 2015 en http://www.jornada.unam.mx/2011/11/09/ politica/005n1pol

CEPAL. (2015). Informe: Panorama Social de América Latina 2014. Naciones Unidas. Comisión Económica Para América Latina (CEPAL). Santiago de Chile. Chile. Consultado el 3 de abril del 2015 en http://repositorio.cepal. org/bitstream/handle/11362/37626/S1420729_es.pdf?sequence=4

CIDH. (2013). Derechos humanos de los migrantes y otras personas en el contexto de la movilidad humana en México. Informe preparado por la por la Relatoría sobre los Derechos de los Migrantes de la Comisión Interamericana de Derechos Humanos. Organización de los estados Americanos (OEA). Washington. Estados Unidos. Dirección electrónica: http://www.oas.org/es/cidh/migrantes/docs/pdf/Informe-MigrantesMexico-2013.pdf, fuente consultada el 25 de enero del 2019.

Clinton, William. (1993). "Remarks ar the Sifning Ceremony for the supplemental Agreements to the North American Free Trade Agreement" American Presidency Project. 1993. Coonsultado en www.presidency. ucsb.edu/ws/?pid=47070

Cord, Louise, Genoni, María Eugenia y Carlos Rodríguez-Castelán. (2015). Prosperidad compartida y fin de la pobreza en América Latina y el Caribe, cuadernillo del Banco Mundial,Washington, DC. Licencia: Creative Commons de Reconocimiento CC BY 3.0 IGO. Consultado el 22 de abril del 2015 en https://openknowledge.worldbank.org/bitstream/ handle/10986/21751/Prosperida_Compartida_Resena.pdf?sequence=7

Cruz, Leticia. (2013). "Violación de mujeres. Costo de la migración: UAM". Agencia de noticias. Imagen del Golfo. Consultado el 2 de mayo del 2015 en http://www.imagendelgolfo.com.mx/resumen.php?id=369765

Debord, Guy. (1994). La sociedad del Espectáculo. Buenos Aires. Argentina. Ediciones Naufragio. Consultado el 2 de abril de 2014 en http://criticasocial.cl/pdflibro/sociedadespec.pdf

Derbez, Luis. (2006). Comunicación personal, Columbia University, New York, New York, abril 2006.

Estrada, Lorena. (2014). Integrante de la organización "El Kilómetro del migrante". 22 de mayo del 2014. Ciudad de México. Entrevista de José Carlos Luque Brazán.

Flores, Linaloe. (2014). "TLCAN, 20 Años: Las Promesas al Olvido," Sin Embargo, enero 1, 2014. Consultado el 16 de septiembre de 2014 enhttp://www.sinembargo.mx/01-01-2014/858398 
Freidman, Milton. (2012). Libre comercio versus proteccionismo. LibertyPen. Canal de YouTube. Consultado el 2 de abril de 2015 en https:// www.youtube.com/watch?v=urSe86zpLI4.

Freudenberg, Nicholas. (2014). Legal but Lethal, New York: Oxford University Press.

Gallo, Rubén. (2004). "Introduction: Delirious Mexico City," in The Mexico City Reader, Gallo, Ed., Madison: The University of Wisconsin Press, Kindle e-book.

Gálvez, Alyshia. (2000). Reporte de Investigación. No publicado. New York University.

Gálvez, Alyshia. (2011). Patient Citizens, Immigrant Mothers, New Brunswick, NJ: Rutgers University Press.

Gálvez, Alyshia. (2018). Eating NAFTA: Trade, Food Policy and the Destruction of Mexico, Oakland: University of California Press.

García, Jacobo. (2017). "La masacre de 72 migrantes que conmovió a Centroamérica, impune siete años después". El País. España. Consultado el 27 de mayo de 2019 en https://elpais.com/internacional/2017/08/23/ mexico/1503503716_558953.html

Kahn, Carrie. (2013). "How NAFTA helped the Mexican Billionaires' Club," Dec. 31, 2013. Consultado el 16 de septiembre de 2014 en http:// www.npr.org/2014/01/01/258668414/how-nafta-helped-the-mexicanbillionaires-club

Klein, Naomi. (2007). The Shock Doctrine, New York: Knopf.

Luque, José. (2014). “Transnacionalismo, migración, ciudadanía y democracia: Una aproximación teórica". Democracia, cultura política y ciudadanía en el México de hoy. Rodríguez Castillo, Luis; Hernández Loaeza, Sergio y Ventura Patiño, María. Programa de Investigaciones Multidisciplinarias Sobre MesoAmérica y el Sureste. Instituto de Investigaciones Antropológicas (IIA). Universidad Nacional Autónoma de México. San Cristóbal de las Casas. Chiapas. Ciudad de México. México.

Mancha, Francisco. (2011). "Nuevos Imaginarios Sociales En Guanajuato: El "Nuevo Migrante" y El Narcotráfico", May 11, presentation at Lehman College, CUNY.

Mandujano, Isaín. (2014). "Riesgo de estallido social, si se sigue criminalizando a jóvenes: Juan Villoro". Revista Proceso. Consultado el 7 de noviembre de 2014 en http://www.proceso.com.mx/?p=383376

Marx, Karl. (1867). Capital: A Critique of Political Economy, I(10), Section 1, p. 257.

Medina Mora, Eduardo. (2014). Comunicación personal con el Embajador de México en Washington, D.C., 30 septiembre. 
Natera, Ximena. (2015). "Migrantes presentan 45 quejas ante la CNDH por forcejeo con autoridades federales". Animal Político. Consultado el 5 de mayo de 2015 en http://www.animalpolitico.com/2015/04/porforcejeo-con-autoridades-federales-migrantes-presentan-45-quejasante-cndh/

Nazario, Sonia. (2006). "Enrique's Journey". Random House. United States.

O'Neill, Shannon. (2012). "What to watch in 2012: The End of Latino Migration?" Latin America's Moment, blog, Council for Foreign Relations, January 3, Consultado el 24 de marzo de 2015 en http://blogs.cfr. org/oneil/2012/01/03/what-to-watch-in-2012-the-end-of-latinoimmigration/

O’Neil, Shannon. (2014). "Council for Foreign Relations, 'NAFTA at 20', Educators' Conference Call, Nov. 6, 2014.

Passel, Jeffrey, D’vera, Cohn y González-Barrera, Anna. (2012). Net Migration from Mexico Falls to Zero-and Perhaps Less. Pew Research Center, April 23. Consultado el 25 de marzo de 2014 en http://www. pewhispanic.org/2012/04/23/net-migration-from-mexico-falls-to-zeroand-perhaps-less/, accessed

Pezzini, Mario. (2014). "An emerging middle class". Organización para la Cooperación y el Desarrollo Económicos (OCDE). Washington. D.C. Estados Unidos. Observer. Consultado el 10 de septiembre de 2014 en http:// www.oecdobserver.org/news/fullstory.php/aid/3681/An_emerging_ middle_class.html

Ramírez, Telésforo y Manuel Castillo. (2012). El Estado de la Migración: México ante los recientes desafíos de la migración internacional. (Coordinadores). Consejo Nacional de Población (CONAPO). Ciudad de México. pp. 1-346.

Reardon, Thomas, and Julio Berdegué. (2000). "The Rapid Rise of Supermarkets in Latin America: Challenges and Opportunities for Development." Develop-ment Policy Review 20, No. 2, pp. 371-88.

Reguillo, Rossana. (2011). "La narcomáquina y el trabajo de la violencia: Apuntes para su decodificación". Revista E-misférica. No. 8.2. Instituto Hemisférico de Performance \& Política de la Universidad de Nueva York. Consultado el 24 de marzo de 2014 en http://hemisphericinstitute.org/ hemi/es/e-misferica-82/reguillo

Rivera, Alex. (2008). "Sleep Dealer". Maya Entertainment. Estados Unidos. Consultado el 24 de marzo del 2014 en https://www.youtube.com/ watch?t=21\&v=nbJGQl-dJ6c.

Rojas-Suarez, Liliana. (2009). Growing Pains in Latin America: An Economic Growth Framework as Applied to Brazil, Colombia, Costa Rica, Mexico and Peru (2009). Available at SSRN. Consultado el 23 de enero del 2014 en http://ssrn.com/abstract=2560941 or http://dx.doi.org/10.2139/ ssrn. 2560941 
Stiglitz, Joseph. (2012). El precio de la desigualdad. El 1 \% de población tiene lo que el 99 \% necesita. Editorial Taurus. Madrid. España.

Taussig, Michael. (1980). The Devil and Commodity Fetishism, Raleigh: University of North Carolina Press. United States.

Traill, Bruce. (2006). "The Rapid Rise of Supermarkets." Development Policy Review. 24, No. 2, pp. 163-74.

Valdés, Guillermo. (2013). El nacimiento de un ejército criminal. Nexos, 1 de septiembre. Consultado el 12 de abril del 2015 en http://www.nexos. com.mx/?p=15460

Voltaire. (1901). In J. Morley (Ed.), The works of voltaire, A contemporary version. New York: E.R. DuMont.

Wise, Timothy. (2014). "How beer explains 20 years of NAFTA's devastating effects on México". Jan. 2, 2014, Global Post. Consultado el 24 de marzo de 2015 en http://ase.tufts.edu/gdae/Pubs/rp/GC68Jan14Wise.pdf

Zepeda, Mayra. (2014). “¿Qué ocurrió en Tlatlaya minuto a minuto, según la CNDH?", Animal Político. Consultado el 2 de mayo del 2015 en http:// www.animalpolitico.com/2014/10/la-matanza-del-ejercito-en-tlatlayasegun-la-cndh/

\section{RESUMEN CURRICULAR DE LOS AUTORES}

\section{Alyshia Gálvez}

Profesora de antropología en New School, New York, y en Lehman College de la Universidad de la Ciudad de Nueva York. Se recibió de doctora en antropología en New York University en 2004. Es autora de tres libros: Eating NAFTA: Trade, Food Policies and the Destruction of Mexico, Berkeley: University of California Press (2018); Nueva York Guadalupana, Puebla: Editorial de la Universidad Iberoamericana de Puebla (2013), traducción de Translation of Guadalupe in New York Devotion and the Struggle for Citizenship Rights among Mexican Immigrants. New York: New York University Press (2009); y Patient Citizens, Immigrant Mothers: Mexican Women, Public Prenatal Care, and the Birth-weight Paradox, New Brunswick: Rutgers University Press (2011). Actualmente está enseñando y haciendo trabajo de investigación acerca del nexo entre migración, salud, y trauma.

Dirección electónica: ALYSHIA.GALVEZ@lehman.cuny.edu 
José Carlos Luque Brazán

Profesor del Colegio de Humanidades y Ciencias Sociales de la Universidad Autónoma de la Ciudad de México, es egresado del doctorado en ciencias políticas y sociales de la Universidad Nacional Autónoma de México, es miembro de la Red Latinoamericana de Estudios Subnacionales (RELADES). Es autor y co-autor de diversos libros y artículos científicos, entre los que destacan: Ayotzinapa. Entre la fragilidad institucional y la violencia del crimen organizado, Anuario Latinoamericano Ciencias Políticas y Relaciones Internacionales, Facultad de Ciencia Política, Universidad Maria Curie-Skłodowska (UMCS), Polonia (2016); Rediseñando las fronteras de lo político: procesos, actores e instituciones políticas del transnacionalismo migrante, Universidad Autónoma de la Ciudad de México (2015); Política en Movimiento: Estado, Ciudadanía y Migración en América. Universidad Nacional Autónoma de México (2013). Líneas de trabajo: Dimensión política de la migración; violencia política y nuevas configuraciones de la ciudadanía.

Dirección electrómica: jose.luque@uacm.edu.mx 